\title{
Programa comunitário de hemoglobinopatias hereditárias em população estudantil brasileira*
}

\section{Public health programs for hereditary hemoglobinopathies in high school students in Brazil}

\author{
Mariane B. Compri, Newton C. Polimeno, Mércia B. Stella e Antônio S. Ramalho \\ Departamento de Ciências Fisiológicas da Faculdade de Ciências Médicas da Universidade São \\ Francisco. Bragança Paulista, SP - Brasil (M.B.C.; N.C.P.; M.B.S.), Departamento de Genética Médica da \\ Faculdade de Ciências Médicas da Universidade Estadual de Campinas. Campinas, SP - Brasil (A.S.R.)
}

\begin{abstract}
Resumo
Foram testadas a viabilidade e a eficiência de um programa comunitário de investigação em hemoglobinopatias, focalizando estudantes de primeiro e segundo graus, de Bragança Paulista, Estado de São Paulo, (Brasil). A triagem das hemoglobinopatias foi oferecida em caráter opcional, sendo realizada pela eletroforese de hemoglobinas e exames hematológicos complementares. Em um período de 24 meses foram examinados 1.118 estudantes e 53 parentes dos mesmos, em um total de 1.171 pessoas. Foram diagnosticados 47 indivíduos com alterações hereditárias da hemoglobina ( 4,0\% da amostra examinada). A comunidade de estudantes mostrou razoável receptividade ao programa, com índice geral de aceitação à realização dos exames laboratoriais de 55,4\%. A investigação despertou o interesse da comunidade, levando à implantação de um serviço especializado de diagnóstico, orientação e tratamento de hemoglobinopatias hereditárias na cidade onde a pesquisa foi realizada.
\end{abstract}

Talassemia, epidemiologia. Doença da hemoglobina SC, epidemiologia. Doença da hemoglobina C, epidemiologia. Avaliação de programas.

\begin{abstract}
This study tested the viability and efficiency of a hereditary hemoglobinopathy program in which a Brazilian community the town of Bragança Paulista, SP (Brazil) - was involved, were tested focusing school students. The screening of the hemoglobinopathies was done through optional exams for patients by using electrophoresis of hemoglobins and complementary hematological tests. A total of 1,171 individuals, including, 1,118 pupils and 53 of their relatives were tested over a period of 24 months. A total of 47 individuals with hereditary hemoglobin changes were detected $-4.0 \%$ of the samples examined. The community was fairly receptive to the program which showed a general level of acceptance of $55.4 \%$. The study aroused the interest of the community and motivated the implantation of a special service for diagnosis, genetic counseling and treatment of the hemoglobinopathy carriers in the community where it was undertaken.
\end{abstract}

Thalassemia, epidemiology. Hemoglobin SC disease, epidemiology. Hemoglobin $S$ disease, epidemiology. Program evaluation.

\footnotetext{
* Trabalho baseado na Dissertação de Mestrado apresentada ao Instituto de Biologia da UNICAMP, em 1995, pela primeira autora deste artigo. Correspondência para / Correspondence to: Mariane B. Compri - Departamento de Ciências Fisiológicas da Faculdade de Ciências Médicas da Universidade São Francisco. Av. São Francisco de Assis, 218 - 12900-000 Bragança Paulista, SP - Brasil. Fax: 7844-1825 E- mail: usfbib@eu.ansp.br Edição subvencionada pela FAPESP. Processo 95/2290-6.

Recebido em 4.5.1995. Aprovado em 14.11.1995.
} 


\section{INTRODUÇÃO}

As hemoglobinopatias hereditárias estão incluídas dentre as doenças genéticas mais freqüentes nas populações humanas. Esse fato contribuiu para que tais doenças tenham sido as primeiras para as quais foram implantados programas comunitários de investigação e controle, sobretudo nos países mais desenvolvidos do Hemisfério Norte. A criação de programas dessa natureza nos países do Terceiro Mundo vem sendo estimulada por vários organismos internacionais, como a Organização Mundial da Saúde $\left(\mathrm{WHO}^{20}, 1983\right)$, a Academia de Ciências de Terceiro Mundo (TWAS ${ }^{17}, 1986$ ) e a Organização Panamericana da Saúde (OPS ${ }^{9}$, 1987). De fato, na medida em que as doenças infecciosas e a desnutrição vão sendo controladas, as hemoglobinopatias vêm emergindo como um dos mais importantes problemas de Saúde Pública dos países do Terceiro Mundo.

Embora as hemoglobinopatias constituam assunto complexo, em geral aceita-se o fato de elas serem agrupadas em duas classes: as hemoglobinopatias estruturais e as por deficiência de síntese ou talassemias. Atualmente, mais de seiscentas hemoglobinas anômalas são conhecidas. Da mesma forma, já foram descritas várias dezenas de síndromes talassêmicas. Apesar disso, apenas duas hemoglobinopatias estruturais (as hemoglobinas $\mathrm{S}$ e $\mathrm{C}$ ), que na forma heterozigótica são encontradas em 6\% e 1\%, — respectivamente nos negróides brasileiros e uma hemoglobinopatia por deficiência de síntese (talassemia beta), cuja frequiência atinge $1 \%$ dos caucasóides paulistas, também quando na forma heterozigótica, — são importantes em nível de saúde pública no Brasil (Ramalho ${ }^{11}$, 1986).Os homozigotos dessas hemoglobinopatias apresentam quadro de anemia hemolítica crônica, incurável (embora tratável), e muitas vezes fatal na infância. A talassemia alfa, apesar de freqüente entre negróides brasileiros, na forma em que ocorre no Brasil (talassemia alfa + ) apresenta pequena relevância clínica (Sonati e col. ${ }^{15}$, 1991).

Tendo em vista a gravidade clínica dos homozigotos das hemoglobinopatias e a alta freqüência dos heterozigotos, a triagem destas entidades genéticas tem ganho espaço junto aos programas comunitários. As atividades de triagem, embora possam resultar em medidas preventivas, têm objetivos primordialmente assistenciais e não eugênicos (Ramalho e col. ${ }^{13}$, 1992). Como comenta Beiguelman ${ }^{3}$ (1979), os princípios de aconselhamento genético, ao contrário do que acontece com os princípios eugênicos, visam, primordialmente, à defesa dos interesses dos indivíduos e das famílias, e não os da sociedade.

Embora os objetivos dos programas comunitários de hemoglobinopatias sejam a base para o desenvolvimento dos mesmos, dependendo do grupo populacional a ser abordado, a metodologia a ser utilizada deve passar por processo de adaptação, levando-se em consideração as características do grupo a ser trabalhado. Além disso, há que se considerar as implicações psicológicas que uma triagem genética acaba por levar. A idade mais apropriada para realização da triagem das hemoglobinopatias é muito controvertida, uma vez que a faixa etária em que a população é mais acessível nem sempre é a mais apropriada para o fornecimento da orientação genética. Entretanto, um programa realizado em estudantes de primeiro e segundo graus oferece a vantagem de conscientização desse grupo antes da idade reprodutiva, implicando assim, além do alcance dos objetivos assistenciais, também dos preventivos.

A viabilidade e a eficiência desses programas dependem basicamente da receptividade da população que, por sua vez, está diretamente relacionada com fatores econômicos, psicológicos e socioculturais extremamente complexos. Nesse sentido, a investigação desta receptividade e, como consequiência, da eficiência de um programa comunitário frente a diferentes grupos populacionais, torna-se relevante, pois permitirá direcionar tais programas a grupos cuja aceitação seja mais adequada.

O presente trabalho teve por objetivo geral investigar a viabilidade e a eficiência de um programa comunitário de Saúde Pública em hemoglobinopatias hereditárias, desenvolvido a partir de uma amostra da população estudantil de primeiro e segundo graus de Bragança Paulista, a fim de que os resultados obtidos pudessem ser comparados com os de um outro programa desenvolvido nos mesmos moldes, cuja abordagem foi realizada a partir de gestantes da cidade de Araras, SP (Teixeira e Ramalho ${ }^{16}$, 1994).

Os seguintes indicadores, adaptados de Teixeira e Ramalho ${ }^{16}$ (1994), prestaram-se como objetivos mais específicos do presente estudo:

1 - Taxa de receptividade aos exames.

2 - Índice de positividade das hemoglobinopatias nos estudantes examinados.

3 - Percentagem de estudantes com hemoglobinopatias que trouxeram outros parentes para exame.

4 - Número médio de pessoas examinadas a partir de cada estudante portador de hemoglobinopatia. 
5 - Índice de positividade das hemoglobinopatias entre os parentes dos estudantes portadores de hemoglobinopatias.

6- Índice de positividade das hemoglobinopatias na amostra total.

7- Percentagem da população de Bragança Paulista examinada em 24 meses pelo programa.

\section{CASUÍSTICA E MÉTODO}

A coleta de dados do presente trabalho teve inicio em 1993 e finalizou-se em 1994. Durante os dezesseis meses letivos foram enviados 2.074 convites a estudantes de dez escolas da rede estadual e particular de Bragança Paulista, sendo 864 desses convites enviados a estudantes de escolas classificadas como de nível socioeconômico superior (Grupo A) e 1.210 convites foram enviados a estudantes de escolas classificadas como de nível socioeconômico inferior (Grupo B).

Os convites foram distribuídos ao longo de todas as séries, desde o ciclo básico até o terceiro ano do segundo grau, abrangendo uma faixa etária que variou de 6 a 22 anos, salvo algumas exceções. Atendendo ao disposto no artigo 123 do Código de Ética Médica (CREMESP 5 , 1988), a autorização para a realização dos exames laboratoriais foi solicitada por escrito aos estudantes ou, no caso dos menores de idade, aos seus responsáveis. Os objetivos da pesquisa, que visam à proteção da saúde pública da comunidade, foram especificados na carta-convite, como rege o artigo 125 do referido Código de Ética Médica. A participação dos estudantes foi voluntária e isenta de qualquer conotação financeira*, política, racial ou eugênica.

A metodologia desenvolvida pode ser dividida nas seguintes fases:

\section{Fase I - Seleção das Escolas que Poderiam Participar do Programa}

Através da Delegacia de Ensino de Bragança Paulista foram selecionadas, com base apenas na distribuição geográfica, 17 escolas da rede estadual e particular, de modo a atingir todos os pontos principais da cidade: Norte, Sul, Leste, Oeste e Centro. A partir da autorização dos respectivos diretores dessas escolas, procedeu-se à organização de um cronograma para a abordagem dos estudantes das séries propostas.

\section{Fase II - Abordagem dos Estudantes Junto às Escolas}

Ministrou-se aos estudantes de cada série convidada a participar do programa uma palestra sobre anemias, enfocando-se especialmente as anemias hereditárias, adequando-se a linguagem da exposição à faixa etária a se trabalhar, com base na teoria de Jean Piaget (Glueck ${ }^{6}$, 1993). Dessa forma, foram ministradas um total de 66 palestras, 29 das quais no grupo A e 37 no grupo B.
Após a palestra, os estudantes levaram aos seus pais uma carta explicativa do programa, solicitando aos mesmos a autorização para execução dos exames, bem como o preenchimento de um questionário informativo sobre alguns aspectos da saúde de seus filhos. Solicitou-se aos estudantes que devolvessem os questionários, mesmo que não desejassem participar do programa.

\section{Fase III - Coleta e Execução dos Exames}

De posse da autorização dos pais ou responsáveis foi colhido de cada estudante, através do sistema "vacuntainer", cinco $\mathrm{ml}$ de sangue venoso, utilizando-se EDTA como anticoagulante. Nessas amostras de sangue foram executados os seguintes exames: hemograma completo, eletroforese de hemoglobinas em gel de agarose em $\mathrm{pH}$ alcalino, teste simplificado de resistência globular osmótica (solução de $\mathrm{NaCl}$ a $0,4 \%$ ), dosagem da fração $\mathrm{A}_{2}$ para confirmação da talassemia minor, teste de solubilidade para confirmação da hemoglobina $S$, teste de desnaturação alcalina para confirmação da hemoglobina fetal e eletroforese em gel de ágar, $\mathrm{pH}$ ácido para confirmação da hemoglobina C. Os exames acima mencionados foram realizados no Núcleo de Hematologia da Uuniversidade São Francisco (USF).

\section{Fase IV - Entrega dos Resultados dos Exames Para os Estudantes}

Os resultados dos exames foram encaminhados aos estudantes, segundo três possibilidades:

a - Resultados normais em todos os exames.

b - Alterações hematológicas não relacionadas com hemoglobinopatias hereditárias. Os estudantes, neste caso, foram encaminhados ao Núcleo de Hematologia da USF.

c - Heterozigotos para hemoglobinopatias. Os pais ou responsáveis pelo estudante foram convidados para orientação genética, sendo esta fornecida de forma didática, utilizando-se, entre outros recursos, jogos e uma linguagem apropriada ao nível cultural de cada orientado. Posteriormente, os mesmos foram convidados a realizar seus exames e de toda a família gratuitamente. Após a execução dos mesmos, na entrega dos resultados, foram distribuídos folhetos explicativos sobre o traço da hemoglobinopatia em questão (AT, AS ou AC).

A avaliação dos resultados realizou-se segundo os indicadores adaptados de Teixeira e Ramalho ${ }^{16}$ (1994), já citados anteriormente.

As análises estatísticas foram realizadas pela comparação de proporções pelo teste do $\mathrm{X}^{2}$, considerando-se $5 \%$ como nível de significância. Quando necessário, utilizouse também o teste exato de Fisher. Essas análises foram realizadas por microcomputador, fazendo-se uso do programa Microstat (Ecosoft Inc., 1984). 
Tabela 1 - Taxa de receptividade aos exames nas escolas dos grupos A e B.

\begin{tabular}{|c|c|c|c|c|c|}
\hline \multicolumn{6}{|c|}{ Grupo A - Nível Socioeconômico Superior } \\
\hline Grau & Convite & $\begin{array}{c}\text { Resposta } \\
\text { Sim }\end{array}$ & $\begin{array}{c}\text { Resposta } \\
\text { Não }\end{array}$ & $\begin{array}{c}\text { Sem } \\
\text { Retorno }\end{array}$ & $\begin{array}{c}\text { Receptividade } \\
\text { Em }(\%)\end{array}$ \\
\hline $1^{\circ}$ & 602 & 279 & 189 & 134 & 46,3 \\
\hline $2^{\circ}$ & 262 & 178 & 61 & 23 & 67,9 \\
\hline Total Grupo A & 864 & 457 & 250 & 157 & 52,9 \\
\hline \multicolumn{6}{|c|}{ Grupo B - Nível Socioeconômico Inferior } \\
\hline $1^{\circ}$ & 872 & 529 & 177 & 166 & 60,7 \\
\hline $2^{\circ}-$ & 338 & 164 & 65 & 109 & 48,5 \\
\hline Total Grupo B & 1.210 & 693 & 242 & 275 & 57,3 \\
\hline Total Geral A e B & 2.074 & 1.150 & 492 & 432 & 55,4 \\
\hline
\end{tabular}

\section{RESULTADOS}

\section{Taxa de Receptividade aos Exames}

A Tabela 1 resume os resultados obtidos nas escolas dos grupos A e B nos primeiros e segundos graus. A receptividade das escola de nível social B foi significativamente maior que a observada nas escolas de nível A $\left(\mathrm{X}^{2}(1)=3,913\right.$; Prob. = 0,0479).

A análise da receptividade por grau de ensino revelou que no primeiro grau do grupo A a receptividade foi significativamente menor do que a observada no segundo grau deste mesmo grupo $\left(X^{2}(1)=34,16 ; 0,01\right.$ $<$ Prob. < 0,001). Já no grupo B, a receptividade do primeiro grau foi significativamente maior do que a verificada no segundo grau $\left(\mathrm{X}^{2}(1)=14,68 ; 0,01<\right.$ Prob. $<0,001)$.

\section{Índice de Positividade das Hemoglobinopatias}

A Tabela 2 apresenta o índice de positividade das hemoglobinopatias entre os estudantes. Conforme é possível verificar a frequiência total de traços hemo- globínicos não diferiu significativamente entre os grupos A e B $\left(X^{2}(1)=0,265 ;\right.$ Prob. $\left.=0,6070\right)$.

\section{Percentagem de Estudantes com Hemoglobinopatias}

Na Tabela 3 verifica-se que a proporção de estudantes que trouxeram outros parentes para exame foi significativamente maior no grupo A $(8 / 8=100 \%)$ do que no grupo B $(7 / 15)=46,6 \%$. (Probabilidade exata de Fisher $=0,0131$ ).

Tabela 2 - Índice de positividade das hemoglobinopatias AS, AC e AT nos estudantes examinados dos grupos A e B.

\begin{tabular}{lcccc}
\hline \multicolumn{5}{c}{ Traços } \\
\hline Grupos & AS & AC & AT & Total \\
\hline Grupo A & $-\overline{0}$ & $-\overline{0}$ & 8 & 8 \\
$\mathrm{n}=447$ & $(0 \%)$ & $(1,8 \%)$ & $(1,8 \%)$ \\
Grupo B & 7 & 2 & 6 & 15 \\
$\mathrm{n}=671$ & $(1,0 \%)$ & $(0,3 \%)$ & $(0,9 \%)$ & $(2,2 \%)$ \\
\hline Total & 7 & 2 & 14 & 23 \\
$\mathrm{n}=1.118$ & $(0,6 \%)$ & $(0,2 \%)$ & $(1,2 \%)$ & $(2,0 \%)$ \\
\hline AS $=$ traço falciforme & & & & \\
AC $=$ traço de hemoglobina $\mathrm{C}$ & & & \\
AT = traço de talassemia beta & & &
\end{tabular}

Tabela 3 - Exames realizados entre familiares dos casos-índice entre estudantes, grupos A e B.

\begin{tabular}{|c|c|c|c|c|}
\hline Grupos & Hemoglobinopatia & $\begin{array}{c}\mathrm{N}^{0} \text { de Casos - } \\
\text { Índice }\end{array}$ & $\begin{array}{c}\text { Comparecimento } \\
\text { das famílias e } \\
\mathrm{N}^{\circ} \text { Indivíduos } \\
\end{array}$ & $\begin{array}{c}\text { Valores } \\
\text { em } \\
\% \\
\end{array}$ \\
\hline \multirow{3}{*}{ A } & AT & 8 & 8 (32 indivíduos) & $100 \%$ \\
\hline & AS & - & - & - \\
\hline & $\mathrm{AC}$ & - & - & - \\
\hline Total A & AT, AS, AC. & 8 & 8 (32 indivíduos) & $100 \%$ \\
\hline \multirow{3}{*}{ B } & AT & 6 & 3 (10 indivíduos) & $50 \%$ \\
\hline & AS & 7 & 3 (9 indivíduos) & $42,8 \%$ \\
\hline & $\mathrm{AC}$ & 2 & 1 ( 2 indivíduos) & $50 \%$ \\
\hline Total B & AT, AS, AC. & 15 & (21 indivíduos) & $46,7 \%$ \\
\hline Total Geral & $\mathrm{AT}, \mathrm{AS}, \mathrm{AC}$. & 23 & 15 (53 indivíduos) & $65,2 \%$ \\
\hline
\end{tabular}


Número Médio de Pessoas Examinadas a Partir de Cada Estudante Portador de Hemoglobinopatia

- Grupo A: $32 / 8=4,0$

- Grupo B: $21 / 7=3,0$

Total A e B : $53 / 15=3,53$

\section{Índice de Positividade das Hemoglobinopatias Entre os Parentes dos Estudantes Portadores}

Na Tabela 4, a partir do número de pessoas examinadas para cada tipo de traço hemoglobínico detectado, calculou-se o índice de positividade das hemoglobinopatias entre os parentes dos estudantes.

$\mathrm{O}$ índice de positividade dos traços entre os parentes não diferiu significativamente entre os grupos A e B $\left(X^{2}(1)=0,725\right.$; Prob.=0,3944). Como é possível verificar, entre os parentes dos estudantes que compareceram para os exames não foram detectados homozigotos para os genes das hemoglobinopatias.

\section{Índice de Positividade das Hemoglobinopatias na Amostra Total}

Conforme dados apontados nos índices anteriores verifica-se que foram detectados 23 estudantes portadores de hemoglobinopatias nos 1.118 exames executados nos escolares e 24 parentes destes estudantes nos outros 53 exames, compondo uma amostragem total de 1.171 exames executados. Portanto, o índice neste tópico proposto pode ser assim expresso:

Índice de positividade geral : 47/1.171 $=0,040$ ou $4,0 \%$.

\section{Percentagem da População Examinada em 24 (vinte e quatro) Meses pelo Programa:}

- Tal percentagem é de 1.171/ $110.000=0,0106$ ou $1,06 \%$.

\section{DISCUSSÃO E CONCLUSÕES}

Na Tabela 5 é apresentada uma comparação geral entre os programas desenvolvidos a partir de gestantes de Araras e de estudantes de Bragança Paulista, a partir da qual será desenvolvida a discussão do presente trabalho.

Do ponto de vista preventivo, o programa de estudantes é teoricamente ideal, uma vez que a detecção dos heterozigotos e a sua orientação genética são feitas antes que eles tenham estabelecido vínculos reprodutivos. No entanto, alguns estudos de avaliação dos efeitos da orientação genética têm demonstrado que, na prática, ela tem pouca influência na escolha do futuro cônjuge (Barrai e Vullo², 1980; Angastiniotis e col. ${ }^{1}, 1986$; Modell $^{8}, 1990$ ).

Por esse motivo, o aspecto educacional e o assistencial dos programas comunitários de hemoglobinopatias são mais relevantes do que o aspecto eugênico. De fato, um indivíduo detectado como portador de um traço de hemoglobinopatia e devidamente orientado quanto às implicações dessa condição, seja pela orientação genética, seja pela leitura do folheto explicativo, estará apto a tomar no futuro as decisões que lhe forem convenientes. Quanto a esse aspecto, a avaliação dos efeitos cognitivos e pragmáticos da orientação genética fornecida na UNICAMP a portadores da talassemia minor, revelou resultados extremamente satisfatórios $\left(\right.$ Serra $\left.^{14}, 1994\right)$.

Tabela 4 - Índice de positividade das hemoglobinopatias entre os parentes dos estudantes portadores de hemoglobinopatias nos grupos A e B.

\begin{tabular}{lccc}
\hline \multirow{2}{*}{ Grupo } & Hemoglobinopatia & $\begin{array}{c}\mathrm{N}^{\circ} \text { de Índivíduos } \\
\text { examinados a partir dos } \\
\text { casos-índice }\end{array}$ & Índice de positividade \\
\hline \multirow{3}{*}{ A } & AT & 32 & 16 indivíduos (50,0\%) \\
& AS & - & - \\
\hline Total A & AC & - & 16 indivíduos $(50,0 \%)$ \\
\hline \multirow{2}{*}{ B } & AT, AS, AC. & 32 & 4 indivíduos $(40,0 \%)$ \\
& AT & 10 & 4 indivíduos $(44,44 \%)$ \\
\hline Total B & AS & 9 & 0 indivíduo $(0 \%)$ \\
\hline Total Geral & AC & 2 & 8 indivíduos $(38,09 \%)$ \\
\hline
\end{tabular}

AS $=$ traço falciforme

$\mathrm{AC}=$ traço de hemoglobina $C$

AT $=$ traço de talassemia beta 
Tabela 5 - Comparação entre os programas de gestantes (Araras) e estudantes (Bragança Paulista).

\begin{tabular}{|c|c|c|}
\hline Dado Diferencial & Gestantes* & Estudantes \\
\hline População abordada & toda & exclui analfabetos \\
\hline Fluxo de triagem & contínuo & período letivo \\
\hline Média mensal de exames & $\begin{array}{l}\text { menor } \\
(56)\end{array}$ & $\begin{array}{l}\text { maior } \\
(70)\end{array}$ \\
\hline $\begin{array}{l}\text { Relação com o estabelecimento de vínculos } \\
\text { reprodutivos pelos propósitos }\end{array}$ & posterior & $\begin{array}{c}\text { anterior } \\
\text { (vantagem teórica) }\end{array}$ \\
\hline $\begin{array}{l}\text { Medidas preventivas ( diagnóstico neonatal, } \\
\text { identificação de casais de risco, de crianças } \\
\text { homozigotas, etc.) }\end{array}$ & curto prazo & longo prazo \\
\hline Impacto educacional & menor & maior \\
\hline Acesso aos propósitos & $\begin{array}{l}\text { mais fácil e mais } \\
\text { rápido }\end{array}$ & $\begin{array}{c}\text { mais trabalhoso e mais } \\
\text { demorado }\end{array}$ \\
\hline Receptividade pelos propósitos & $\begin{array}{l}\text { maior } \\
(100 \%)\end{array}$ & $\begin{array}{l}\text { menor } \\
(55,4 \%)\end{array}$ \\
\hline Positividade dos traços nos propósitos & $\begin{array}{c}\text { maior } \\
(3,6 \%) \\
(>\text { negróides })\end{array}$ & $\begin{array}{c}\text { menor } \\
(2 \%) \\
(<\text { negróides })\end{array}$ \\
\hline $\begin{array}{l}\text { Índice de triagem ( } \mathrm{n}^{\circ} \text { - médio de pessoas examinadas } \\
\text { a partir de cada propósito) }\end{array}$ & $\begin{array}{c}\text { maior } \\
(5,6)\end{array}$ & $\begin{array}{c}\text { menor } \\
(3,5)\end{array}$ \\
\hline Positividade dos traços nos parentes dos propósitos & $\begin{array}{c}\text { igual } \\
(45,5 \%)\end{array}$ & $\begin{array}{c}\text { igual } \\
(45,3 \%)\end{array}$ \\
\hline Índice de positividade dos traços na amostra total & $\begin{array}{c}\text { maior } \\
(13,5 \%) \\
\text { (> consangüíneos dos propósitos) }\end{array}$ & $\begin{array}{c}\text { menor } \\
(4 \%) \\
(<\text { consangüíneos dos } \\
\text { propósitos })\end{array}$ \\
\hline
\end{tabular}

* Estudo de Teixeira e Ramalho ${ }^{16}(1994)$

$\operatorname{Kessler}^{7}$ (1989), revisando a literatura posterior a 1979 a respeito dos aspectos educacionais e reprodutivos dos programas de aconselhamento genético, verificou que, a despeito das diferenças metodológicas, esses programas geralmente alcançam os seus objetivos no que se refere aos aspectos educacionais, à informação sobre o diagnóstico e o risco genético. Já no que se refere às decisões reprodutivas após o aconselhamento genético, eles não revelam uma eficiência semelhante. Isso também foi observado no trabalho de Serra ${ }^{14}$ (1994).

No que se refere à taxa de aceitação à realização dos exames, o trabalho junto aos estudantes revelou que a receptividade nas escolas de nível social inferior $(57,3 \%)$ foi significativamente maior que a observada nas escolas de nível social superior $(52,9 \%)\left(X^{2}(1)=3,91 ;\right.$ Prob. $\left.=0,0479\right)$. A diferença verificada entre os índices de aceitação dos grupos A e B era prevista, e poderia ser ainda mais significativa ao se considerar o poder aquisitivo maior do grupo A, que apresenta, por este motivo, uma certa resistência à participação em programas comunitários; este fato talvez seja compensado por seu nível de instrução, maior do que o observado no grupo B. Este, com poder aquisitivo menor, parece ser mais interessado em participar de programas dessa natureza. Entretanto, existe, no que se refere ao conheci- mento da importância desses programas, maior dificuldade de compreensão. Se for considerada a receptividade dos estudantes, frente aos graus de ensino, verifica-se que a receptividade no primeiro grau do grupo A foi significativamente menor do que no segundo grau deste mesmo grupo. Por outro lado, no grupo B este perfil se inverteu, ou seja, a receptividade do primeiro grau foi significativamente maior do que no segundo grau. Estes dados indicam que existe um interesse maior dos pais dos alunos do primeiro grau do grupo B, para que seus filhos realizem seus exames, provavelmente devido às condições econômicas do grupo. Com relação ao segundo grau do grupo B os pais parecem não excercer tanta influência sobre as decisões dos estudantes. No grupo $\mathrm{A}$, os pais dos estudantes do primeiro grau não manifestaram tanto interesse em que seus filhos realizassem os exames, talvez porque os mesmos tenham condições de o fazerem em serviços particulares. A maior receptividade do segundo grau no grupo A deverá ter sido, portanto, devido à maior compreensão da importância da realização dos exames pelos estudantes.

Enquanto a abordagem da população a partir de gestantes oferece várias vantagens de ordem pragmática, que vão desde o fato de as gestantes já realizarem rotineiramente o hemograma em seu segui- 
mento pré-natal, até o aspecto psicológico da preocupação com a saúde da criança, na abordagem a partir de estudantes o quadro é completamente diferente. $\mathrm{O}$ convite à realização do exame de sangue foi feito a estudantes que, ao menos aparentemente, gozavam de saúde, e que, na sua grande maioria, não pretendiam submeter-se a tal exame naquele momento. Nesse sentido, o trabalho de conscientização da importância das anemias, e a clareza das explicações do que são as anemias, quais são os tipos principais e o fato de algumas delas, como a talassemia minor, aparecerem de forma subclínica em alguns períodos, é fundamental para que se "convença" o estudante a participar do programa. Assim, as palestras realizadas a cada classe no momento de enviar os convites à participação, visavam ao esclarecimento dos estudantes, e também ao estabelecimento de um clima de confiança junto ao programa. No programa desenvolvido em Araras não houve recusa à realização dos exames entre as gestantes atendidas nos postos de saúde municipais, nem nas atendidas nas clínicas particulares. Dos 2.209 convites realizados, todos foram aceitos, o que mostra um índice de aceitação de $100 \%$, enquanto no presente trabalho, dos 2.074 convites enviados foram aceitos 1.150 (índice de aceitação geral $=55,44 \%$ ). Assim, em termos de indicadores de viabilidade e eficiência, o programa desenvolvido a partir das gestantes é significativamente mais viável e mais eficiente do que o programa desenvolvido junto à população estudantil $\left(X^{2}(1)\right.$ $=155,369 ;$ Prob. $\left.=7,5256 \cdot 10^{-11}\right)$. Esta conclusão é perfeitamente justificável, tendo em vista as considerações feitas anteriormente sobre as vantagens de se desenvolver o programa junto a gestantes, e as dificuldades em fazê-lo junto à população de estudantes. Não é demais lembrar que para a realização dos exames nos estudantes menores de idade, além do estudante aceitar fazer os exames, os pais e/ou responsáveis também tiveram que concordar; portanto, temos aqui duas etapas de receptividade, considerando-se que a maioria dos estudantes convidados eram menores.

A percentagem da população de Bragança Paulista examinada em 24 meses pelo programa foi de $1,073 \%$. No programa de Araras, junto às gestantes, tal percentagem atingiu o valor de 3,7\%, lembrando-se, no entanto, que ele foi desenvolvido durante 51 meses. Além disso, a abordagem junto aos estudantes implica em detalhes, como palestras, solicitações de autorização para exame, entre outros, que acabam por determinar um maior despendimento de tempo, enquanto que a abordagem realizada junto às gestantes dispensa tais procedimentos.
No programa de estudantes não foram detectados doentes portadores de hemoglobinopatias hereditárias, como ocorreu no programa de gestantes. Evidentemente, tal objetivo do programa de estudantes só será possível de ser alcançado a longo prazo, tendo em vista os resultados benéficos da orientação genética que continuará sendo fornecida à comunidade.

Um dado até certo ponto esperado do presente trabalho, é que não foram detectados na amostra total casais de risco, ou seja, casais constituídos por dois heterozigotos. Esse fato não é surpreendente, tendo em vista o número relativamente pequeno de casais examinados. Realmente, todos os casos-índice diagnosticados como portadores de traços de hemoglobinopatia eram menores de idade e solteiros e o comparecimento dos seus pais para exame também não foi dos mais significativos. No trabalho de gestantes, foram detectados 16 casais de risco, dos quais 12 ainda encontravam-se em idade reprodutiva, e 5 tinham um filho portador de hemoglobinopatia clinicamente importante. Neste aspecto, o programa junto aos estudantes parece que alcançará o seu objetivo também apenas a longo prazo.

$\mathrm{O}$ índice de positividade dos traços hemoglobínicos entre os estudantes dos grupos $\mathrm{A}$ e $\mathrm{B}\left(\mathrm{X}^{2}(1)=\right.$ $0,265$; Prob. $=0,6070)$ não diferiu significativamente. No entanto, enquanto no grupo A, de maior nível socioeconômico, foram diagnosticados apenas portadores do traço talassêmico beta, no grupo B foram diagnosticados portadores dos traços de hemoglobinas S e C $(9 / 15=60 \%)$, bem como portadores do traço talassêmico beta $(6 / 15=40 \%)$. Da mesma forma, a proporção de portadoras dos traços hemoglobínicos AS e AC no programa de gestantes foi significativamente maior entre as gestantes heterozigotas diagnosticadas nos postos de saúde municipais $(88,9 \%)$ do que nas clínicas particulares (50\%). Com relação ao traço talassêmico beta, a proporção de gestantes heterozigotas diagnosticadas nas clínicas particulares $(50 \%)$ também foi significativamente maior do que nos postos de saúde municipais $(11,1 \%)$.

Os resultados obtidos nos programas de estudantes e gestantes são concordantes quanto a maior proporção de negróides na subamostra de menor nível socioeconômico e quanto à maior participação de caucasóides descendentes de italianos na subamostra de maior nível socioeconômico. De fato, enquanto os heterozigotos $\mathrm{AS}$ e $\mathrm{AC}$, mais freqüentes entre negróides, preponderaram entre os estudantes de menor nível socioeconômico, os heterozigotos AT, mais freqüentes entre caucasóides, preponderaram entre os 
estudantes de maior nível socioeconômico. Quando se compara a proporção de heterozigotos AS + AC frente ao total de heterozigotos diagnosticados (9/23) no programa de estudantes com esta mesma proporção verificada no programa de gestantes (61/80), o índice de positividade dos traços AS + AC é significativamente maior no programa de gestantes do que no de estudantes $\left(\mathrm{X}^{2}(1)=11.304\right.$; Prob. $\left.=7,732 \cdot 10^{-4}\right)$. Deste modo, a amostra de gestantes provavelmente tem um contingente de negróides maior do que o verificado na amostra dos estudantes.

$\mathrm{O}$ índice geral de positividade dos traços hemoglobínicos verificado entre os estudantes foi de $2,05 \%$. Tal valor é significativamente menor do que o observado por Teixeira e Ramalho ${ }^{16}$ (1994) entre as 2.209 gestantes examinadas na cidade de Araras, ou seja, 3,6\% $\left(X^{2}(1)=6,06\right.$; Prob. $\left.=0,0139\right)$. Este fato talvez possa ser justificado se for considerado que na amostra de gestantes foram examinados número maior de consangüíneos dos propósitos.

A divulgação nas comunidades brasileiras dessas importantes entidades, que são as hemoglobinopatias hereditárias, deverá contribuir para que se estabeleça uma mentalidade que, embora preventiva, seja também bem orientada, uma vez que o diagnóstico e o tratamento precoce dessas doenças melhoram significativamente o seu prognóstico, aumen-

\section{REFERÊNCIAS BIBLIOGRÁFICAS}

1. ANGASTINIOTIS, M.; KYRIAKIDOV, S.; HADJIMINAS, M. Como se há combatido la talassemia en Chipre. Foro Mundial Salud, 7: 312-9, 1986.

2. BARRAI, I. \& VULLO, C. Assessment of prospective genetic counseling in the Ferrara Area. Am. J. Med. Genet., 6: $195-204,1980$.

3. BEIGUELMAN, B. O aconselhamento genético. Ciênc. $e$ Cult., 31: 136, 1979.

4. BOWMAN, J. Prenatal screening for hemoglobinopathies. Am.J.Hum.Genet., 48: 433-8, 1991.

5. CONSELHO REGIONAL DE MEDICINA DO ESTADO DE SÃO PAULO. Código de ética médica. São Paulo, 1988.

6. GLUECK, M.I.R. Um trabalho interdisciplinar com base na teoria de Jean Piaget. Rev.Psicopedag., 12: 19-22, 1993.

7. KESSLER, S. Pyschological aspects of genetic conseling: a critical review of literature dealing with education and reproduction. Am.J.Med.Genet., 34: 340-53, 1989.

8. MODELL, B. Etica del diagnostico prenatal y asesoramento genético. Foro Mundial Salud, 11: 179-86, 1990.

9. ORGANIZACIÓN PANAMERICANA DE LA SALUD. Ejecución de acciones de salud en genetica; informe de un Comité de Expertos en Genetica Médica. Habana, Cuba, 1987. tando a expectativa e a qualidade de vida dos seus portadores. Com relação à anemia falciforme, por exemplo, que é a doença hereditária mais freqüente no Brasil (Ramalho, ${ }^{11}$ 1986; Paiva e Silva e Ramalho $\left.{ }^{10}, 1993\right)$, está perfeitamente demonstrado que algumas medidas simples, como a penicilinoterapia profilática e a vacinação antipneumocócica, se tomadas precocemente, aumentam a sobrevida dos pacientes (Vichinsky e col. ${ }^{18}$, 1988; Bowman ${ }^{4}$, 1991). Estudo realizado por Wong e col. ${ }^{19}$ (1992), nos EUA, mostrou que houve aumento de dez vezes da população adulta, com anemia falciforme, devido à vacinação antipneumocócica e à penicilinoterapia profilática em crianças com menos de dois anos de idade. Da mesma forma, o diagnóstico precoce dos portadores da talassemia major e o seu tratamento com hipertransfusão sangüínea e quelação do ferro aumentam significativamente a sua sobrevida e diminuem as seqüelas e complicações clínicas (Ramalho $\left.{ }^{12}, 1986\right)$.

\section{AGRADECIMENTOS}

Aos bioquímicos do Núcleo de Hematologia e Hemoterapia da Universidade São Francisco, Maria Julia Acedo Vieira, Vânia Aparecida Costa e Rodney Vieira Veloso, pela valiosa colaboração.

10. PAIVA E SILVA, R.B.; RAMALHO, A.S.; CASSORLA, R.M.S. A anemia falciforme como problema de saúde pública no Brasil. Rev.Saúde Pública, 27: 54-8, 1993.

11. RAMALHO, A.S. As hemoglobinopatias hereditárias: um problema de saúde pública no Brasil. Ribeirão Preto, Editora da Revista Brasileira de Genética, 1986.

12. RAMALHO, A.S. A talassemia minor como causa de anemia no Estado de São Paulo. Rev.Bras. Patol., 22: 32-8, 1986.

13. RAMALHO, A.S.; MARTINS, C.S.B.; PAIVA E SILVA, R.B. Aspectos médicos do aconselhamento genético, com especial ênfase às hemoglobinopatias hereditárias. Campinas, 1992. [Publicação avulsa do Departamento de Genética Médica da Faculdade de Ciências Médicas da Universidade Estadual de Campinas].

14. SERRA, H.G. Avaliação da orientação genética fornecida a portadores da talassemia minor, Campinas, 1994. [Dissertação de Mestrado - Universidade Estadual de Campinas].

15. SONATI, M.F.; FARAH, S.B.; RAMALHO, A.S.; COSTA, F.F. High prevalence of alpha-thalassemia in a Black population of Brazil. Hemoglobin, 15: 309-11, 1991.

16. TEIXEIRA, R.C. \& RAMALHO, A.S. Genetics and public health : response of Brazilian population to an optional hemoglobinopathy program. Rev.Bras.Genet., 17: 435-8, 1994. 
17. THIRD WORLD ACADEMY OF SCIENCES. Final Report: South North Round Table on Haemoglobinopathies, Trieste, 1986.

18. VICHINSKY, E.; HURST, D.; EALES, A.; KLEMAN, K.; LUBIN, B. Newborn screening for sickle cell disease. Effect on mortality. Pediatrics, 81: 749-55, 1988.
19. WONG, W.; POARS, D.R.; CHAN, L.; JOHNSON, C.; OVERTURF, G. Polysaccharide encapsulated bacterial infection in sickle cell anemia: a thirty years epidemiologic experience. Am.J.Hematol., 39: 176-82, 1992.

20. WORLD HEALTH ORGANIZATION. Community control of hereditary anaemias. Memorandum from a WHO meeting Bull. World Health Organ., 61: 63-80, 1983. 